\title{
Article
}

\section{Nurse staffing levels revisited: a consideration of key issues in nurse staffing levels and skill mix research.}

Flynn, Maria and Mckeown, Mick

Available at http://clok.uclan.ac.uk/6245/

Flynn, Maria and Mckeown, Mick ORCID: 0000-0003-0235-1923 (2009) Nurse staffing levels revisited: a consideration of key issues in nurse staffing levels and skill mix research. Journal of Nursing Management, 17 (6). pp. 759-766. ISSN 1365-2834

It is advisable to refer to the publisher's version if you intend to cite from the work. http://dx.doi.org/10.1111/j.1365-2834.2009.01023.x

For more information about UCLan's research in this area go to http://www.uclan.ac.uk/researchgroups/ and search for <name of research Group>.

For information about Research generally at UCLan please go to http://www.uclan.ac.uk/research/

All outputs in CLoK are protected by Intellectual Property Rights law, including Copyright law. Copyright, IPR and Moral Rights for the works on this site are retained by the individual authors and/or other copyright owners. Terms and conditions for use of this material are defined in the policies page.

\section{CLoK}

Central Lancashire online Knowledge www.clok.uclan.ac.uk

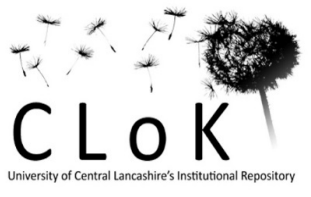




\section{Title Page}

Title of Paper - Nurse Staffing Levels Revisited: A consideration of key issues in nurse staffing levels and skill mix research.

\section{Authors}

Maria Flynn

Senior Lecturer

School of Health Sciences

Faculty of Medicine

University of Liverpool

Liverpool L69 3GB

UK

Mick McKeown

Principal Lecturer

Department of Nursing

University of Central Lancashire

Preston

UK

\section{Corresponding Author}

Dr Maria Flynn

School of Health Sciences

Thompson Yates Building

University of Liverpool

Liverpool L69 3GB

E: $\underline{\text { m.flynn@ @liverpool.ac.uk }}$ 
Nurse Staffing Levels Revisited: A consideration of key issues in nurse staffing levels and skill mix research.

\section{Abstract}

\section{Aims}

This paper revisits the published evidence relating to how nurse staffing levels impact on service outcomes and considers the implications of this body of research for nurse managers in their quest to determine optimum nursing establishments.

\section{Background}

Within the context of the recognised global nursing shortage and particular local pressures within international health services, questions of appropriate nurse staffing levels and skill mix are once again becoming increasingly important. It would seem that the determination of optimum nurse staffing levels and skill mix is a central issue in relation to health service governance, service user involvement, as well as in the recruitment, retention and well being of nursing staff across the service sectors.

\section{Evaluation}

A review of published evidence was carried out, applying key principles of the systematic method, in order to facilitate the identification of current factors and issues in nurse staffing levels research. The review did not seek to address a specific research question. The search covered 10 years from 1998-2008 and identified more than five hundred relevant papers, giving a wide international perspective.

\section{Key issues}

The majority of research in the field relates to the acute service sector and there are considerable similarities in issues that transcend international boundaries. Much of the research focuses on the impact on patients and nurses of 'poor' nurse staffing 
levels. More recent studies have explored the impact of nurse staffing levels on the service organisation itself. However, whilst there may be an association between models of nurse staffing and outcomes, there is insufficient evidence to establish a causal relationship between these factors. In this context it is perhaps time to reconsider how nursing outcomes are defined and measured.

\section{Conclusions \& implications for nursing management}

Nurse managers, commissioners of services and workforce planners need to be cognisant of key issues and analyses in the consideration of nurse staffing levels. Not least of these is the need for a healthy degree of caution regarding the supposed objectivity, scientific basis, or evidence base, for rational calculation of optimum nurse staffing levels.

\section{Key Words (up to 5)}

Nurse staffing levels, skill mix, nurse workforce, staff-patient ratios, nursing outcomes 


\section{Introduction}

In the context of a recognised global nursing shortage, and particular demographic pressures on the UK nursing workforce (Buchan 2002, Chaguturu \& Vallabhaneni 2005) there has been an increasing interest in the issue of nurse staffing levels and skill mix. This is in conjunction with a broader set of concerns around safety and risk minimisation (Scott 2003, Page 2004, Naish 2006, Torangeau Cranley \& Jeffs 2006, Rafferty et al 2007) and, indeed, the professional role and identity of nurses in society and the extent to which nursing's impact might be valued and measured (Maben \& Griffiths 2008, Griffiths et al 2008). In the UK health service there has been a creeping tendency towards the employment of temporary, agency and bank nursing staff, especially in metropolitan areas (House of Commons 2007). The UK NHS as a whole has witnessed a fragmentation of its organisation, with a decentralisation of power to Trusts and Foundation Trusts (Mannion et al 2005) against a backdrop of marketisation (Toynbee 2005) and managerialism, coupled with cost reduction pressures (Kirkpatrick \& Ackroyd 2003). In this paper we review the research relating to the impact of nurse staffing levels on various outcomes and suggest implications for nurse managers and others interested in optimising nursing establishments.

\section{Background}

The literature suggests that there are a number of deleterious consequences associated with inadequate workforce planning in terms of nurse staffing, with lower numbers of registered nurses often associated with worsened patient outcomes (Aiken et al 2002, Needleman et al 2002, Torangeau et al 2002, Estabrooks et al 2005, Torangeau et al 2006, Torangeau Cranley \& Jeffs 2006, Rafferty et al 2007). Solutions to problems with workforce are arguably given over to appeals to a scientific basis for structuring the nursing workforce, involving approaches to 
measuring acuity or patient dependency linked to various models for estimating appropriate nurse staffing levels and skill mixes.

Nursing staffing models can be broadly described as those which rely on professional judgement and expertise, those that utilise staffing norms and the computation of a statistical relationship between independent variables and those which adopt measurement techniques by timing nursing interventions and tasks or seeking to classify patient dependency (Arthur and James 1994, Hurst 2003).

It is recognised that for over forty years a considerable amount of effort has been invested into developing nurse staffing models, however, the question remains as to their overall utility and relevance to modern health service provision. No nurse staffing or skill mix model has been conclusively demonstrated to address all the variables which impact on nursing workload, nor have they been shown to be causally related to patient, nurse or organisational outcomes.

This is perhaps not surprising, as nurse staffing models inevitably rely on the collection of local data, much of which is constructed by subjective professional judgements and measures of nurse activity or patient dependency (Hurst 2003). In addition, the process of data collection itself can increase nursing workloads, as the data have to be collected by nursing staff themselves or by external 'observers'. In this context it is debateable whether staffing models can be effective tools for nurse managers or if they have merely gained credibility and assumed utility through custom and practice.

Similarly, nursing has been traditionally and philosophically concerned with notions of care and dependency; yet it is debatable whether these are the real issues driving the governance of nurse staffing levels and skill mixes. In parallel with nursing 
concerns, there is a growing influence of service user movements in health and social care, which are perhaps equally interested in the impact of nurse staffing levels and skill mix on quality of care. Scepticism amongst professional and trade unions, especially around notions of scientific management, suggest that disputes over the conduct and results of staffing level review processes could possibly be a major future nexus for tension in industrial relations. Taken together, the latter points raise the potential for resistive alliances between nursing and service user activists.

\section{Identification and Evaluation of Issues}

In order to devise a strategy for identifying current issues in nurse staffing levels research, several conceptual factors had to be acknowledged. In relation to an understanding of what constitutes 'appropriate skill mix' and 'minimum staffing levels' the operational definitions of these concepts has to be considered within the wider socio-cultural, political, economic, professional and service users contexts. However, this is not necessarily a straightforward undertaking and there is a degree of tension evident within these various contexts.

For example, a health service economist or director of finance may consider a minimum nurse staffing level and appropriate skill mix to be one which is sufficient to maintain patient safety at all times. However, a professional nurse working within an environment where there are only enough staff to ensure that no harm occurs to patients, may find the accepted 'minimum staffing level' itself to be a primary cause of job-dissatisfaction and work related stress (Chang et al 2005). Similarly, nurse managers may believe an appropriate nursing skill mix is one which has a high ratio of registered nurses to health care assistants, and may therefore struggle to appoint enough of the desired grades of staff within their nursing establishment budget. 
In addition to these considerations there are also specific process factors that will impact on the design and conduct of any review of evidence. These include the conduct and reporting of research per se, the existence of 'hierarchies of evidence', publication biases, language constraints and reviewer biases, all of which must be acknowledged (Chalmers \& Altman 1995, Greenhalgh \& Peacock 2005). In the case of this search and review the aim was to identify key factors and issues that need to be considered by those making decisions about nurse staffing levels and skill mix. Effectively this meant that we were evaluating what Edwards et al (2001) have described as the 'signal' and 'noise', which emanates from the literature, rather than attempting to extract data for analysis.

The period covered by the search included the years $1998-2008$, which roughly corresponds to the time frame when the impact of major UK government health policy initiatives, including the NHS Plan (DH 2000) and the Patient led NHS (DH 2005), are being felt within all sectors of the UK health service. Although it is recognised that there has been a considerable amount of work devoted to nursing skill mix, workload estimation and appropriate staffing levels from the 1960's onwards (Arthur \& James 1994), this work was not included in our review. We acknowledge that these early ideas and concepts will have informed current research and debate, but they can no longer have direct contextual relevance to modern and re-organised health services, and so were therefore excluded.

The search strategy comprised a broad-based search and accessed electronic databases available through the University libraries. Keywords used in the searches included Nurse, nursing, staff, staffing, staffing levels, workload, workforce, skills mix, staff-patient ratios, outcomes, patient outcomes and adverse incidents. Using Boolean operators the key words were repeatedly combined to refine the searches. 
The refined searches produced a total of 584 systematic reviews and meta-analyses, research reports, literature reviews and policy papers which were pertinent to the subject area of the review. The search was extensive, in terms of both content and international coverage; however, as the review was not designed to address a specific research question it did not proceed to data extraction and synthesis of individual study findings.

The research literature showed a wide and growing international coverage of questions of nurse staffing levels and skill mix, however, it is acknowledged that international health care systems differ considerably in both philosophy and economics. Therefore only research studies addressing issues that could transcend international boundaries were included in this review.

\section{International Issues in Nurse Staffing Research}

The research literature related to questions of nurse staffing levels covers global research, including work carried out in the UK, Scandinavia, the EU, Australia, North America, Thailand, Singapore, Israel, Kuwait and Canada. It was interesting to note that the majority of research studies relate to nursing in the acute hospital sector, but there is also literature to be found relating to public health and community nursing, mental health nursing, midwifery and nursing homes (Hurst 2006, Konetzka et al 2008). Throughout the service sectors the studies used a range of methods in order to explore the relationships between nurse staffing levels and skill mix to patient, nurse, organisational and economic outcomes.

Research has focused on nurse staffing levels \& skill mix associated with particular patient groups (Kovner, Jones \& Zahn 2002, Upeniecks et al 2007) patient safety, mortality or adverse outcomes (Sasichay-Akkadechanunt et al 2003, Rafferty et al 
2007, Garrett 2008, Sochalski et al 2008), patient satisfaction (Tervo-Heikkenen et al 2008), nurse safety, nurse job satisfaction (Aiken et al 2002), sickness, absenteeism, recruitment and retention, organisational issues, the working environment (Budge, Carryer and Wood 2003, Stone, Du and Gershon 2007, Aiken et al 2008, Unruh 2008) and health economics (Thungjaroenkul, Cummings and Embleton 2007).

There are similarities in reported findings across international boundaries, with one study (Rafferty et al 2007) explicitly comparing North American nurse staffing ratios and patient outcomes with UK survey data. Through a cross sectional analysis this study examined the effects of nurse staffing levels on mortality and failure to rescue alongside reported nurse job satisfaction. It found that lower patient-to-nurse ratios produced consistently better outcomes, for both nurses and patients. It also found that despite the considerable differences in the health systems of the UK and the USA, the impacts of nurse staffing levels were similar.

Other literature, principally from Australia and the US (Donaldson et al 2005, Gerdtz \& Nelson 2007, Upenieks et al 2008), reports on the effects of the implementation of statutory minimum 'nurse-patient' ratios, which exceed those in the UK. However, it is interesting to note that these ratios have often required militant industrial action to be implemented. It is also of interest that the majority of international research studies appear to be exploring the impact of 'poor' staffing levels or skill mixes, rather than seeking to develop or evaluate innovative ways of working.

It may be that in the context of the international shortage of nurses (Buchan 2002) and the changing expectations of patients and service users, the challenge for the profession is to reconsider what constitutes an appropriate and relevant measure of nursing work, and indeed what outcomes, for both patients and nurses, are indicative of 'good' nursing. 


\section{Patient Outcomes}

A majority of the international research studies appear to have sought to relate (usually adverse) patient outcomes to nurse staffing levels and skill mix. Measures which have been used as patient outcome indicators have included mortality, hospital acquired infections, falls, pressure ulcers, suicide, length of hospital stay, medication errors, post-operative complications or infection rates and serious adverse incidents such as cardiac or respiratory arrest (for example Sasichay-Akkadechanunt et al 2003, Eastbrooks et al 2005, Rafferty et al 2007, Tourangeau et al 2007, Garrett 2008, Sochalski et al 2008).

In relation to nurse staffing levels and patient outcomes two systematic reviews of evidence were found. Lankshear, Sheldon and Maynard's (2005) review assessed the evidence for a relationship between the nursing workforce and patient outcomes in the acute sector. The search covered the years 1990 - 2004 and included both published and grey literature. This systematic review synthesised the findings from twenty-two large studies. The results suggested that higher levels of nurse staffing and a skill mix rich in qualified nurses are associated with improved patient outcomes. However, it is important to note that Lankshear and colleagues (2005) were not able to reliably estimate the effect size of this association. Also of some relevance was their suggestion of the need for research that elucidates the actual mechanisms by which nursing care affects patient outcomes.

Kane, Shamliyan, Mueller, Duval and Wilt's (2007) systematic review and metaanalysis was designed to assess the evidence of an association between registered nurse staffing levels and patient outcomes. Twenty-eight studies were eligible for inclusion in the analysis and the pooled data showed significant associations 
between higher numbers of qualified nurses and a reduction in hospital related mortality and adverse patient events. These included lower patient mortality and hospital-acquired infections, lower risk of failure to rescue in surgical patients, lower risk of respiratory or cardiac emergencies in ICU and reduced length of stay in ICU and surgical patients. Whilst this evidence makes a strong case for increased numbers of qualified nurses to deliver care, the reviewers also noted that 'contextual factors' such as the hospital management and their commitment to quality of medical care are also likely to have an important impact on patient outcomes. Kane et al (2007) suggest that these extrinsic factors should therefore be considered as part of the causal pathway in determining optimum nurse staffing levels and skill mix.

Both these systematic reviews show an association between nurse staffing levels and patient outcomes, but it is interesting to note how the reviewers qualify their findings, and indicate the importance of contextual factors in determining optimum nurse staffing levels. It is perhaps the case that until such time as internationally agreed outcome measures are identified and adopted it will continue to be difficult to conclusively demonstrate a causal relationship between nurse staffing levels and skill mix and patient outcomes.

\section{Nurse Outcomes}

A smaller, though still comprehensive, part of the international research literature relates to nurse staffing levels and skill mix and the impact these have on nurses themselves. These types of studies are largely designed to identify associations between nurse staffing levels and skills mix, the consequences these have for nursing workload, and how workload then impacts on nurses' wellbeing. 
The measures used to assess 'nurse outcomes' also tend toward identifying adverse outcomes. They include such measures as incidence of physical injury, exposure to aggression and violence, levels of sickness and absenteeism, self-reports of job satisfaction or dissatisfaction and burnout (for example Hegney et al 2003, Moyle et al 2003, Morgan et al 2005, Robinson et al 2005, Sheward et al 2005, Al-Kandari and Thomas 2008).

As with the 'patient outcomes' research, the range and quality of the studies varies, and much of it relates to the acute service sector. There were no systematic reviews of evidence we identified which related to staffing levels and skill mix and nurse outcomes.

Although the association between nurse staffing levels and adverse nurse outcomes may be intuitively attractive there is little evidential basis for this causal link to be made. Evidence to support this assumed association would have to be demonstrated through systematic review or empirical testing.

It is also interesting to note that much of the literature relating to the impact of workload, staffing levels and skill mix on nurses themselves can be seen to be concerned with protecting the position of registered nurses against a perceived or potential 'threat' from health care assistants or other health care practitioners. This issue of substitution across staff of different grades and disciplines has always been around in health care services but might arguably become more prevalent in the near future of impending economic downturn and squeeze on public spending. This could create interesting dilemmas for professional and trade unions seeking to organise both registered and unregistered nurses, a goal which has, latterly, been adopted to some degree by the Royal College of Nursing. 


\section{Organisational Issues and the Working Environment}

Three systematic reviews were identified which related to nurse staffing levels and organisational issues. Lang, Hodge, Olson, Romano and Kravitz (2004) reviewed the effects of nurse staffing on patient, nurse and hospital outcomes, Pearson, Pallas, Thomson et al (2006) evaluated the impact of nurse workload and staffing on establishing healthy working environments, whilst Thungjaroenkul, Cummings and Embleton (2007) reviewed the impact of nurse staffing on hospital costs and patient length of stay.

Much of the available information about the association between organisational factors and nurse staffing and skill mix is inherent in research that has another primary focus, such as patient or nurse outcomes. However, there is a growing body of work emerging from the Joanna Briggs Institute in Adelaide (Australia) that is specifically concerned with the quality of the working environment in healthcare settings. The systematic review reported by Pearson et al (2006) was designed to weigh the evidence for a relationship between nurse staffing levels and healthy working environments. The results of the review suggested 'strong correlations' between the characteristics of patients and work environments and also between nursing workload, staffing levels and the quality of outcomes for nurses, patients and the organisation.

Lang et al (2004) sought to examine whether the evidence supported minimum nurse-patient ratios for acute hospitals by reviewing research findings between 1980 and 2003 where patient outcome measures were limited to adverse events. The review found that high nurse staffing ratios were associated with lower inpatient mortality and failure to rescue rates as well as reduced length of stay in hospital. However, although the evidence suggested an association between nursing skill mix 
and some important patient outcomes the reviewers concluded that the evidence did not support specific minimum nurse-patient ratios for acute hospitals.

The systematic review reported by Thungjaroenkul et al (2007) was designed to evaluate the evidence of an association between nurse staffing and hospital costs. Although the reviewers note a lack of clarity in the definition and measurement of hospital costs they nonetheless suggest that a nursing skill mix with a higher ratio of qualified nurses could reduce the costs of inpatient episodes. They argue that the educational preparation and knowledge of qualified nurses results in the prevention of adverse patient events and an overall reduction in the consumption of hospital resources by patients.

In relation to the question of optimum nurse staffing levels and skill mix the results of these reviews are not conclusive. Whilst the reviews did appear to show an association between total nursing hours, skill mix and some patient outcome measures, were not able to conclusively demonstrate support for minimum nursepatient ratios in hospital.

\section{Confounding Variables}

It is apparent to us that the quest to demonstrate a causal relationship between nurse staffing levels and skill mix and patient, nurse or organisational outcomes is confounded by what could be described as 'extraneous variables'. Within healthcare environments these include medical care and interventions, material resources and facilities and physical geography. Other factors that may also confound any assumed relationship between nurse workload, staffing levels, skill mix and outcomes would be measures of patient dependency (Hurst 2008) and the use of temporary 'bank' and agency nursing staff. 
In 2001 the UK Audit Commission published their review of standardised data on hospital ward staffing, expenditure and patient outcomes. This review showed massive variation, between and within Trusts, and little evidence that the nursing workforce is either planned or reviewed systematically, or based on patient need. Findings indicated that staffing levels and funding disparities were largely based on historical rather than rational reasons.

In relation specifically to UK health policy, a related matter for consideration has to be the implementation of successive reforms and the perceived or actual fragmentation of the NHS. It is arguable that the establishment of Foundation Trusts and increasing private sector involvement in care delivery are moving the service away from a national consensus on standards of nurse staffing and could possibly lead to the introduction of local pay bargaining.

It is also interesting to note that a recurrent idea in research relating to nurse staffing and skill mix is the reference to the notion of 'quality of nursing care' (Aiken, Clarke and Sloane 2002, Scott and West 2004). In the research reviewed here, links are often made between patient outcomes and the quality of nursing care, although the construct 'quality of care' is not universally defined. The notion of quality patient care is central to both professional education and practice and in the UK is the principal driver of current health policy as outlined in the Darzi review (DH 2008). If quality patient care is to be a useful element of any workforce planning and nurse staffing negotiations then the construct must be clearly defined and understood by all who provide and use health services. 


\section{Conclusions \& Implications for Nurse Managers}

It appears from this revisiting of the nurse staffing and skill mix research that the findings are not yet robust enough to substantiate a relationship between models of nurse staffing and patient, nurse or organisational outcomes. The extensive international literature includes some systematic reviews of evidence of aspects of nurse staffing, and yet the relationship between nursing skill mix, staffing levels, workload and patient, nurse or organisational outcomes remains largely inconclusive. It also appears that the commonly accepted principles for establishing nurse staffing levels are based on historical data, custom and practice. Nonetheless, the research has demonstrated that the concept of optimum nurse staffing levels and skill mix is a multidimensional one, which needs to be considered within a wider sociocultural context (Currie et al 2005).

There is no substantial empirical evidence to suggest that models for calculating skill mix ratios and nurse staffing levels sufficiently account for other variables relating to the working environment or the organisation of nursing practice (Gerdtz \& Nelson 2007, Hurst 2008) and in terms of the long term industrial relations between the nursing workforce and their mangers this could be problematic. In the absence of robust process for calculating appropriate nurse staffing levels for particular settings and taking into account changing levels of patient need, it is likely that nurse participants will lack confidence in such evaluation exercises. Similarly, their professional and trade unions will remain sceptical that the proposed new systems will offer no more than previous appeals to scientific management which, in their view, amount to efforts to exert control over nurses' work dressed up in an illusory cloak of objectivity (McKeown 1995). 
The UK NHS Next Stage Review (DH 2008) commits to measuring the quality of nursing care in ways that reflect its compassion, safety and effectiveness, and a team at the UK National Nursing Research Unit have begun a process of identifying 'best bets' for the most appropriate indicators for evaluating the nursing contribution (Maben \& Griffiths 2008, Griffiths et al 2008). Despite identifying variation in nurse staffing levels as a prominent factor in relation to various outcomes, we conclude that the inclusion of staffing levels and skill mix in the proposed metrics would, as Griffiths et al (2008) suggest, 'stifle change and create perverse incentives' (p24). It may be more useful to consider the appraisal of actual staffing compared to planned staffing, as this would at the very least ensure that some objective thought has gone into a strategy for nurse staffing levels, and had taken account of particular circumstances (Griffiths et al 2008).

However, perhaps the most pressing conceptual issue for international nurse managers is the need to reconcile a common understanding as to what constitutes an appropriate nursing outcome in any given context. It would appear that until such time as this understanding is reached the best that can be said is that there appears to be an association between the nurse staffing levels and a variety of outcome indicators. Until such time as there are valid and accepted definitions and measures of these outcomes, whether patient, nurse or organisational, it will be difficult for nursing to establish causality or consistently significant associations, and so present a compelling case.

In order to secure the very best quality nursing care there is perhaps a need for nurse managers to question whether the common approaches to determining nursing establishments, skill mix and staffing levels are of real practical use and whether they continue to be appropriate within the context of the drive for 'best evidence' to underpin all aspects of health service organisation and delivery. 


\section{References}

Aiken L, Clarke S, Sloane D, Sochalski J \& Silber J. (2002) Hospital nurse staffing and patient mortality, nurse burnout, and job dissatisfaction. Journal of the American Medical Association, 288 (22), 2948-2954.

Aiken L, Clarke S, Sloan D, Lake E, Cheney T (2008) Effects of hospital care environment on patient mortality and nurse outcomes Journal of Nursing Administration 38 (5), 223-229

Al-Kandari F and Thomas D (2008) Adverse nurse outcomes: correlations to nurses' workload, staffing and shift rotation in Kuwaiti hospitals Applied Nursing Research 21 (3), 139-146

Arthur T \& James N (1994) Determining nurse staffing levels: A critical review of the literature Journal of Advanced Nursing 19, 558-565

Audit Commission (2001) Acute Hospitals Portfolio Review of National Findings: Ward Staffing London Stationery Office

Buchan J (2002) Global Nursing Shortages BMJ 324, 751-752

Budge C, Carryer J and Wood S (2003) Health correlates of autonomy. Control and professional relationships in the nursing work environment Journal of Advanced Nursing 42 (3), 260-268

Chaguturu, S. \& Vallabhaneni, S. (2005) Aiding and abetting - nursing crises at home and abroad. New England Journal of Medicine, 353, 17, 1761-1763.

Chalmers I \& Altman DG (1995) Systematic Reviews London BMJ Publishing

Chang E, Hancock K, Johnson A, Daly J, Jackson D (2005) Role stress in nurses: review of related factors and strategies for moving forward Nursing and Health Sciences 7, 57-65

Currie V, Harvey G, West E, McKenna H and Keeney S (2005) Relationship between quality of care, staffing levels, skill mix and nurse autonomy: literature review Journal of Advanced Nursing 51 (1), 73-82

Department of Health (2000) The NHS plan: A plan for investment and plan for reform London Department of Health

Department of Health (2005) Creating a patient led NHS: Delivering the NHS improvement plan London Department of Health

Department of Health (2008) A high quality workforce. NHS next stage review (the Darzi review) London Department of Health

Donaldson N, Bolton LB, Aydin C, Brown D, Elashoff JD, Sandhu M (2005) Impact of California's licensed nurse-patient ratios on unit-level nurse staffing and patient outcomes Policy, Politics and Nursing Practice 6 (3), 198-210 
Edwards A, Elwyn G, Hood K, Rollnick S (2001) Judging the 'weight of evidence' in systematic reviews: introducing rigour into the qualitative overview stage by assessing signal and noise Journal of Evaluation in Clinical Practice 6 (2), 177-184

Estabrooks, C., Midodzi, W., Cummings, G., Ricker, K. \& Giovannetti, P. (2005) Impact of hospital characteristics on 30-day mortality. Nursing Research 54 (2) 74-84

Fleming K \& Briggs M (2006) Electronic searching to locate qualitative research: evaluation of three strategies Journal of Advanced Nursing 57 (1), 95-100

Garrett C (2008) The effects of nurse staffing patterns on medical errors and nurse burnout AORN 87 (6), 1191-1204

Gerdtz MF and Nelson S (2007) 5-20: A model of minimum nurse-to-patient ratios in Victoria Australia Journal of Nursing Management 15 (1), 64-71

Greenhalgh T \& Peacock R (2005) Effectiveness and efficiency of search methods in systematic reviews of complex evidence: audit of primary sources BMJ 331, 10641065

Hansard (2005) House of Commons written answers for 24 Jan 2005: Column 186W

Griffiths P, Jones S, Maben J \& Murrells T (2008) State of the art metrics for nursing: a rapid appraisal. National Nursing Research Unit, Kings College London: London.

House of Commons Public Accounts Committee (2007) Department of Health: improving the use of temporary nursing staff in NHS acute and foundation trusts. HC142. London The Stationary Office.

Hegney D, Plank A and Parker V (2003) Nursing workloads: the results of a study of Queensland nurses Journal of Nursing Management 11, 307-314

Hurst K (2003) Selecting and applying methods for estimating the size and mix of nursing teams: A systematic review of the literature commissioned by the Department of Health Leeds Nuffield Institute for Health

Hurst K (2006) Primary care workforce planning and development Journal of Advanced Nursing 55 (6), 757-769

Hurst K (2008) UK ward design: Patient dependency, nursing workload, staffing and quality - an observational study International Journal of Nursing Studies 45 (3), 370381

Kane R, Shamlian Tatyana A, Mueller C, Duval S, Wilt TJ (2007) The association of registered nurse staffing levels and patient outcomes: Systematic review and metaanalysis Medical Care 45 (12), 1195-1294

Kirkpatrick, I. \& Ackroyd, S. (2003) Transforming the professional archetype: the new managerialism in the UK public services. Public Management Review, 5(4), 509-529

Konetzka RT, Stearns SC and Park J (2007) The staffing-outcomes relationship in nursing homes Health Services Research 43 (3), 1025-1042 
Kovner C, Jones C and Kahn C (2002) Nurse staffing and post-surgical adverse events:an analysis of administrative data from a sample of US hospitals Health Services Research 37, 611-629

Lang TA, Hodge M, Olson V, Romana PS, Kravitz RL (2004) Nurse-patient ratios: A systematic review on the effects of nurse staffing on patient, nurse employee and hospital outcomes Journal of Nursing Administration 34, p326-337

Lankshear A, Sheldon T, Maynard A (2005) Nurse staffing and healthcare outcomes: A systematic review of the international research evidence Advances in Nursing Science 29 (2), 163-174

Maben J. \& Griffiths P. (2008) Nurses in society: starting the debate. National Nursing Research Unit, Kings College London: London.

Mannion R, Goddard M, Kuhn M \& Bate A (2005) Decentralisation strategies and provider incentives in healthcare: evidence from the English National Health Service. Applied Health Economics and Health Policy 4 (1), 47-54.

McKeown M (1995) The Transformation of Nurses' Work? Journal of Nursing Management 3 (2) 67-73.

Morgan DG, Stewart NJ, D'Arcy C, Forbes D, Lawson J (2005) Work stress and physical assault of nursing aides in rural nursing homes with and without dementia special care units Journal of Psychiatric and Mental Health Nursing 12 (3), 347-358

Moyle W, Skinner J, Rowe G, Gork C (2003) Views of job satisfaction and dissatisfaction in Australian long-term care Journal of Clinical Nursing 12, 168-176

Naish, J. (2006) Setting appropriate ward nurse staffing levels in NHS acute Trusts. London RCN Policy Unit.

Needleman J, Buerhaus P, Mattke S, Stewart M \& Zelevinsky K (2002) Nursestaffing levels and the quality of care in hospitals. New England Journal of Medicine 346 (17) 1715-1722

Page A (2004) Keeping patients safe: transforming the work environment of nurses. Washington DC National Academies Press.

Pearson A, O'Brien Pallas L, Thompson D, Doucette E, Tucker D, Wiechula R, Long L, Porritt K, Jordan Z (2006) Systematic review of evidence on the impact of nursing workload and staffing on establishing healthy working environments International Journal of Evidence Based Healthcare 4 (4), 337-384

Rafferty AM, Clarke SP, Coles J, Ball J, James P, McKee M and Aiken LH (2007) Outcomes of variation in hospital nurse staffing in English hospitals: cross sectional analysis of survey data and discharge records International Journal of Nursing Studies 44 (2), 175-182

Robinson S, Murrells T and Smith EM (2005) retaining the mental health nursing workforce: Early indicators of retention and attrition International Journal of Mental Health Nursing 14, 230-242 
Sasichay-Akkadechanunt T, Scalzi CC, Jawad AF (2003) The relationship between nurse staffing and patient outcomes Journal of Nursing Administration 33 (9), 478485

Scott, C. (2003) Setting safe nurse staffing levels: an exploration of the issues. London RCN.

Scott C and West E (2004) Editorial. Special Issue on the nursing workforce and quality of care Journal of Nursing Management 12 (6), 381-384

Sheward L, Hunt J, Hagen S, McCleod M, Ball J (2005) The relationship between UK hospital nurse staffing and emotional exhaustion and job dissatisfaction Journal of Nursing Management 13 (1), 51-60

Sochalski J, Konetzka RT, Zhu J, Vollp K (2008) Will mandated nurse staffing ratios lead to better patient outcomes? Medical Care 46 (6), 606-613

Stone PW, Du Y and Gershon RR (2007) Organisational climate and occupational health outcomes in hospital nurses Journal of Occupational and Environmental Medicine 49 (1), 50-58

Tervo-Heikkinen T, Kvist T and Partanen P (2008) Patient satisfaction as a positive nursing outcome Journal of Nursing Care Quality 23, 58-65

Thungjaroenkul P, Cummings GC and Embleton A (2006) The impact of nurse staffing on hospital costs and patient length of stay: A systematic review Nursing Economics 25 (5), 255-265

Torangeau A, Giovannetti P, Tu J \& Wood M (2002) Nursing-related determinants of 30-day mortality for hospitalised patients. Canadian Journal of Nursing Research, 33, 4, 71-88.

Torangeau, A., Doran, D., McGillis Hall, L., O'Brien Pallas, L., Pringle, D., Tu, J. \& Cranley, L. (2006) Impact of hospital nursing care on 30-day mortality for acute medical patients. Journal of Advanced Nursing, 57, 32-44.

Torangeau, A., Cranley, L. \& Jeffs, L. (2006) Impact of nursing on hospital patient mortality: a focused review and related policy implications. Quality and Safety in Health Care, 15, 4-8.

Toynbee, P. (2005) Manic marketisation is driving the NHS into cut-throat chaos. The Guardian, Friday October 72008.

Unruh L (2008) Nurse staffing and patient, nurse and financial outcomes American Journal of Nursing 108, 62-71

Upenieks VV, Akhavan J, Kotlerman J, Esser J, Ngo MJ (2007) Value added care: A new way of assessing nurse staffing ratios and workload variability Journal of Nursing Administration 37 (5), 243-252 


\section{Acknowledgement}

This paper has been inspired by a review we undertook for the UNISON National Nursing Sector Committee. The review was commissioned in 2007 and findings were reported in early 2008 . We are grateful for the opportunity to revisit this important professional issue and would like to thank members of the Nursing Sector Committee for their constructive feedback on this paper. 